\title{
The Preparation and Properties of NBR/CNTs Nanocomposites by Emulsion Method
}

\author{
Zheng GU ${ }^{1}$, a, Lei $Z \mathrm{ZHENG}^{1,2}$, Peiyao $\mathrm{LI}^{1}$, Guojun $\mathrm{SONG}^{1}$ and Bidong TU${ }^{1}$, \\ ${ }^{1}$ Institute of polymer materials, Qingdao University,Qingdao,266071, China \\ ${ }^{2}$ Science and Technology Department, Qingdao University, Qingdao,266071, China
}

\begin{abstract}
The NBR/CNTs nanocomposites were prepared by emulsion coprecipitated method, using the self-made CNTs. The effect of the different grades of CNTs on the mechanical properties, curing properties, electrical properties, aging properties and thermal stability were investigated. The results showed that the properties of NBR/CNTs nanocomposite by emulsion coprecipitated method has been greatly improved. The NBR/W2\#CNTs nanocomposites had the best comprehensive properties.
\end{abstract}

\section{Introduction}

In recent years, the development of nanocomposites has become an attractive new subject in materials science. Dependent on the applied type of filler, nanoparticles can influence the electrical and thermal conductivity of the final nanocomposites.carbon nanotubes (CNTs) are believed to be one of the ultimate reinforcement materials for polymer matrix composites, because of their high aspect ratio (up to $10^{4}$ ), specific surface area, Youngs modulus (about $103 \mathrm{GPa}$ ) close to that of diamond, tensile strength of about $50 \mathrm{GPa}$, and light weight (density of about $\left.1.3 \mathrm{~g} / \mathrm{cm}^{3}\right)^{[1-3]}$.

In recent years, The research of polymer/CNTs nanocompistes has made great progress. Wagner et al. The fracture behavior of MWCNTs in the polymer composite film was studied by Wang et al. The stress transfer ability of the interface between the polymer/carbon nanotube was more than $500 \mathrm{MPa}$, which was 10 times higher than that of the carbon fiber reinforced composites. Template method of carbon nanotube array with the epoxy resin/CNTs composite was prepared by template method, which has good antistatic effect. The percolation threshold of the composite is only $0.0025 \%{ }^{[4,5]}$.

At present, carbon black is always an effective reinforcing filler for rubber and still occupy a dominant position in the rubber-reinforcing system. But the CNTs reinforcing modification research reports are relatively less. The main reasons are: firstly, the enhancement mechanism of CNTs in rubber system is still not clear, and the mechanical properties of rubber composites reinforced by CNTs are different. Secondly, CNTs as a one dimensional nano material, is difficult to well disperse in the rubber matrix. Thirdly, CNTs

* Corresponding author:guzheng596@163.com 
reinforced rubber composite material has the disadvantages of low elongation, high viscosity and poor processing performance.

In this study, we prepared NBR/CNTs nanocomposites by emulsion method. The properties of the NBR/CNTs nanocomposites were studied.

\section{Materials}

The CNTs were provided by Institute of Polymer Materials, Qingdao University, China. NBR emulsion(mass fraction of total solid 23\%) was obtained by Lanzhou Petrochemical Company (China). Other materials are commercial products.

\section{Preparation of NBR/CNTs nanocomposites}

The modified CNTs was dispersed in the water (mass fraction of total solid 10\%), then the CNTs suspension was added into NBR emulison and the mixture was vigorously stirred for $30 \mathrm{~min}$ at $60^{\circ} \mathrm{C}$.

The mixture was co-coagulatedwith $10 \%$ calciumcarbonate solution,washed withwaterand dried at $60{ }^{\circ} \mathrm{C}$. The NBR/CNTs nanocomposites were mixed further on a two-roll mill with other ingredients at ambient temperature for about $15 \mathrm{~min}$. The charging order is $\mathrm{ZnO}$ (Zinc Oxide), SA (Stearic Acid), M (2-mercaptobenzothiazole) and sulfur one by one. Finally, the compounds were compression-molded at $145{ }^{\circ} \mathrm{C}$ under $15 \mathrm{MPa}$ for the optimum cure time $\left(\mathrm{T}_{90}\right)$ to yield vulcanizates. Recipes of NBR/CNTs nanocomposites: NBR $100 \mathrm{phr}, \mathrm{ZnO} 5 \mathrm{phr}$, SA $1.5 \mathrm{phr}, \mathrm{M} 1.5 \mathrm{phr}$, Sulfur $2 \mathrm{phr}$; phr is the abbreviation of weight parts per 100 weight parts of rubber.

\section{Characterization}

TEM observation was performed on ultra-thin films prepared by cryoultramicrotomy using a JEM-1200EX (JOEL, Japan) at an acceleration voltage of $80 \mathrm{KV}$.

Tensile tests were carried out on 2 mm thick dumbbells (type: S1 according to DIN 53504) on a DXLL-50000 material tester (Dirs Company, China) at a crosshead speed of $500 \mathrm{~mm} / \mathrm{min}$ and room temperature.

The curing behavior was investigated at $143{ }^{\circ} \mathrm{C}$ using rotorless rheometer MDR2000 (D and G Company, China) according to ISO 6502-1999 with frequency of $1.66 \mathrm{HZ}$.

Thermo-gravimetric analysis (TGA) of the samples was performed using a thermo-gravimetric analyzer (TGA/STDA851, Mettler Toledo, Shanghai, China) attached to an automatic programmer from ambient temperature to $700{ }^{\circ} \mathrm{C}$ at a heating rate of $10^{\circ} \mathrm{C} / \mathrm{min}$ in an air atmosphere. A sample weight of approximately $15 \mathrm{mg}$ was used for the measurement. The temperature reproducibility of the TGA instrument is $\pm 3{ }^{\circ} \mathrm{C}$ and on run for each sample.

The electrical impedance was measured at ambient temperature using LCR meters (HP 4284A, HP4192A, Agilent) with a 16034B test fixture. The two instruments complemented each other in the frequency and impedance ranges: $20 \mathrm{~Hz}$ to $1 \mathrm{MHz}$ and up to $100 \mathrm{MV}$ (HP4284A), and $5 \mathrm{~Hz}$ to $13 \mathrm{MHz}$ with a maximum of $1 \mathrm{MV}$ (HP4192A), respectively. 


\section{Results and Discussion}

\subsection{The morphology of CNTs in NBR matrix}

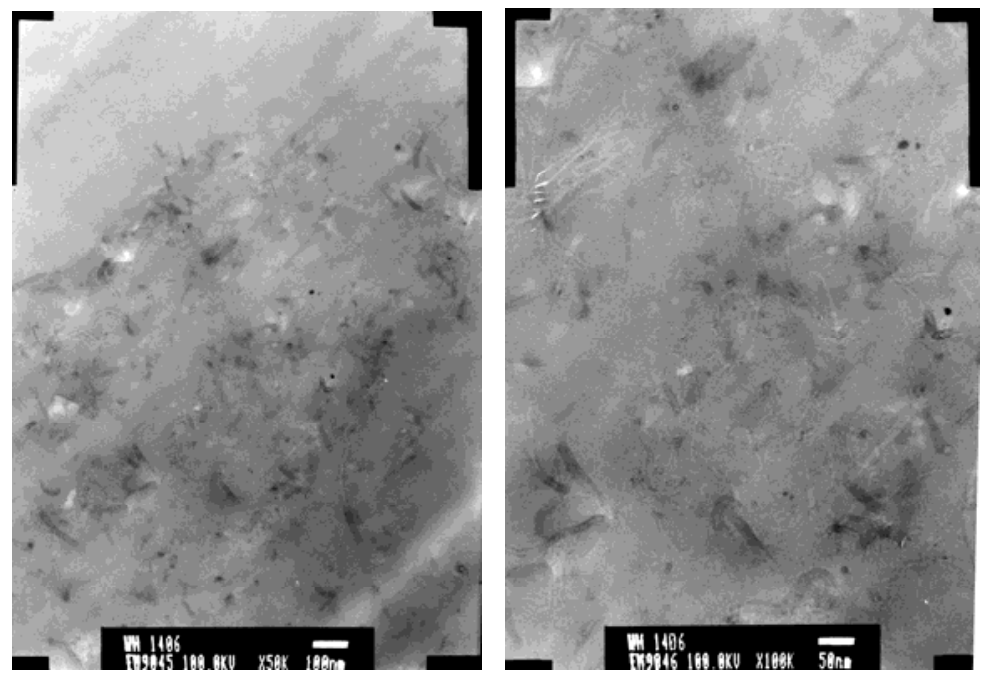

Fig.1: The TEM of NBR/CNTs nanocomposites

As it can be seen from Fig. 1, the CNTs exhibit a high dispersibility in the NBR matrix. The results of TEM showed that the CNTs were dispersed in NBR matrix on nano-scale. The homogeneous dispersion in the NBR matrix was achieved by emulsion method. The amino-groups seem to stabilise the CNTs-dispersion by stronger interactions with the NBR matrix. This can be attributed to the increased polarity of the CNTs by the functional groups and the possible reaction of the amino-groups with the NBR matrix, forming covalent bonds ${ }^{[6]}$.

\subsection{Mechanical properties of NBR/CNTs nanocomposites}

Table 1: The Mechanical Properties Of Nbr/Cnts Nanocompistes

\begin{tabular}{|c|c|c|c|c|}
\hline CNTs & $\begin{array}{c}\text { Modulus at 200\% } \\
\text { (MPa) }\end{array}$ & $\begin{array}{c}\text { Tensile strength } \\
\text { (MPa) }\end{array}$ & $\begin{array}{c}\text { Elongation at break } \\
(\%)\end{array}$ & $\begin{array}{c}\text { Tear strength } \\
\text { (KN/m) }\end{array}$ \\
\hline 0wt\% & 1.58 & 2.32 & 273 & 17.35 \\
\hline W0(3wt.\%) & 1.85 & 3.33 & 246 & 16.76 \\
\hline W11(3wt.\%) & 3.19 & 5.30 & 154 & 26.31 \\
\hline W2(3wt.\%) & 3.18 & 7.68 & 295 & 27.92 \\
\hline W4(3wt.\%) & 3.64 & 6.14 & 274 & 18.99 \\
\hline
\end{tabular}

As can be seen from table1, the mechanical properties of NBR/CNTs nanocompoistes increased greatly compared to the pure NBR. The results showed the values possessed maximum values for $\mathrm{W} 2 \# \mathrm{CNTs}$ content loading of $3 \mathrm{wt} \%$, the tensile strength of the nanocomposites increased from 2.32 to $7.68 \mathrm{MPa}$. The modulus at $200 \%$ and elongation at 
break also increased. And comparing with the values of pure NBR, the nanocomposites with $3 \mathrm{wt} \%$ w2\#CNTs was the best sample associated with its mechanical properties. The enhancement of tensile strength was directly attributed to the strong interaction between the CNTs particles and BR molecular chains, and the effective load transfer from the surrounding the NBR matrix into the CNTs. The addition of small loading CNTs can greatly increase the mechanical properties of NBR/CNTs nanocomposites.

\subsection{The Vulcanization behavior of NBR/CNTs nanocomposites}

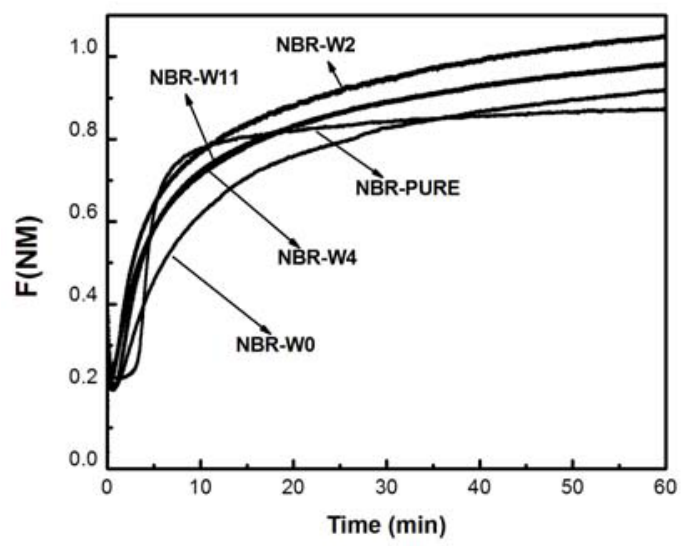

Fig.2: The vulcanization curves of NBR/CNTs nanocomposites

The vulcanization behavior of NBR and its nanocomposites with modified CNTs were shown in Fig. 2. As can be seen from Fig.2, the first stage of the vulcanization curves is the scorch promote, during the accelerator reactions occur. In this stage, compared with the torque of the pure NBR, the NBR/CNTs nanocompistes accelerated. The second phase is the curing reaction while the network structure form. The $T_{90}$ of the NBR/CNTs is much more longer than that of pure NBR. The CNTs decelerated the vulcanization behavior of the NBR/CNTs nanocomposites ${ }^{[7]}$.

\subsection{The electrical properties of NBR/CNTs nanocomposites}

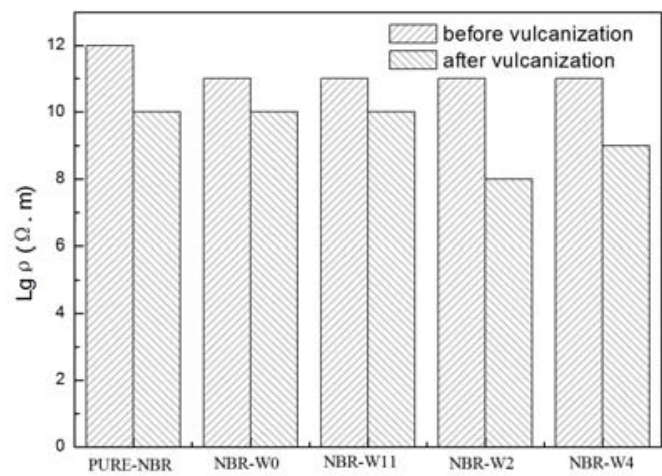

Fig.3: The electrical properties of NBR/CNTs nanocomposites 
As can be seen from Fig.3, before the vulcanization, the surface resistivity of NBR/CNTs nanocomposite redeuced from $10^{12}$ to $10^{11}$, comparing with the pure NBR. After the vulcanization, the conductivity of the NBR/CNTS nanocomposites can be greatly improved. The surface resistivity of NBR/W2\#CNTs decreased from $10^{11}$ to $10^{8}$, which has reached the semiconductor level. The addition of CNTs can effectively reduce the surface resistance of NBR, improve the electrical conductivity of NBR, and the modified W2\#CNTs effect is the best ${ }^{[8]}$.

\subsection{The thermal stability of NBR/CNTs nanocomposites}

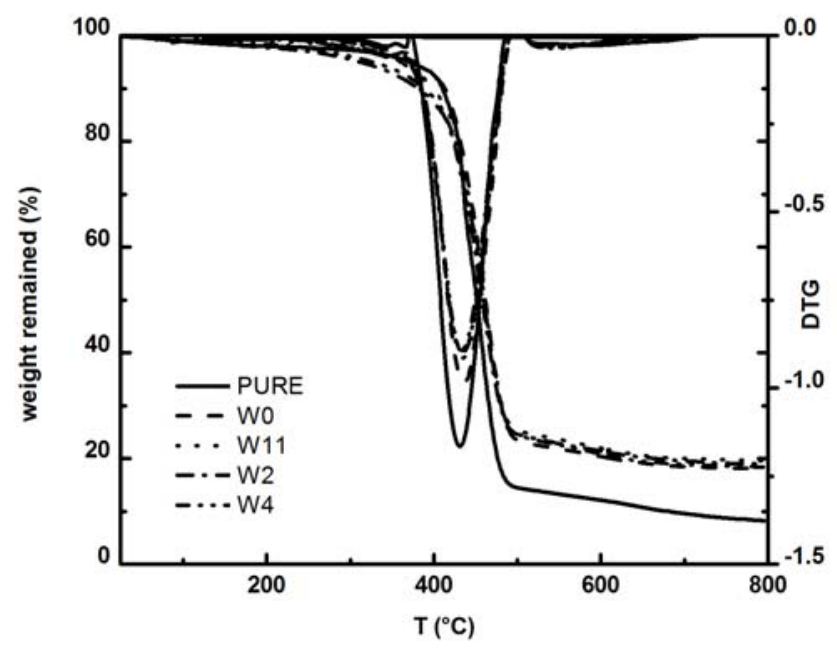

Fig.4: The TG curves of NBR/CNTs nanocomposites

The TG curves of NBR/CNTs nanocomposites are shown in Fig.4. As can be seen from Fig.4, the NBR/CNTs nanocomposites are more stable than pure NBR. The maximum temperature of NBR/CNTs nanocomposites increased $10^{\circ} \mathrm{C}$. This can be mainly attributed to the strong interaction between the NBR matrxi and the CNTs.

\section{Conclusion}

The NBR/CNTs nanocomposites were prepared by emulsion coprecipitated method. the properties of NBR/CNTs nanocomposite by emulsion coprecipitated method has been greatly improved. The NBR/W2\#CNTs nanocomposites had the best comprehensive properties.

\section{Acknowledgments}

The Authors acknowledge the financial support from the project of Shandong province higher educational science and technology program(J14LA18) and the NSFC(Grant Nos.51503111). 


\section{References}

1. Iijima S. Helical microtubules of graphitic carbon. Nature 1991;354:56-58.

2. Oberlin A, Endo M. Filamentous growth of carbon through benzene decomposition. J Cryst Growth 1976;32:335-339.

3. Thostenson ET, Ren Z, Chou TW. Advances in the science and technology of carbon nanotube and their composites: a review. Compos Sci Technol 2001;61:1899-1912.

4. Thostenson ET, Chou TW. On the elastic properties of carbon nanotube-based composites: modeling and characterization. J Phys D: Appl Phys 2003;36:573-582.

5. Yu MF, Lourie O, Dyer MJ, Moloni K, Kelly TF, Ruoff RS. Strength and breaking mechanism of multiwalled carbon nanotubes under tensile load. Science 2000;287:637-640.

6. Xiangwen Zhou, Yuefeng Zhu, Qianming Gong, Ji Liang. Preparation and properties of the powder SBR composites filled with CNTs by spray drying process. Materials Letters 60 (2006) 3769-3775.

7. Xiangwen Zhou, Yuefeng Zhu, Ji Liang. Preparation and properties of powder styrene-butadiene rubber composites filled with carbon black and carbon nanotubes. Materials Research Bulletin 42 (2007) 456-464.

8. L.G. Pedroni, J.R. Araujo, M.I. Felisberti, A.F. Nogueira.Nanocomposites based on MWCNT and styrene-butadiene-styrene block copolymers: Effect of the preparation method on dispersion and polymer-filler interactions.Composites Science and Technology 72 (2012) 1487-1492. 